\title{
Main Drivers for Maritime Cluster and Shipping in the Baltic Sea
}

\author{
Riitta Pöntynen ${ }^{1 *}$, Anne Erkkilä-Välimäki ${ }^{2}$, and Hanna Nieminen ${ }^{3}$ \\ ${ }^{1}$ University of Turku, Centre for Maritime Studies, Finland \\ ${ }^{2}$ University of Turku, Centre for Maritime Studies, Finland \\ ${ }^{3}$ Finnish Environment Institute SYKE, Finland
}

\begin{abstract}
One of the main aims of Maritime Spatial Planning (MSP) is to observe and determine factors affecting the development of various future sea uses. As a part of the transboundary MSP research done in the Maritime Spatial Planning for Sustainable Blue Economies (Plan4Blue) project, drivers for the creation of alternative scenarios for Blue Economy in the Gulf of Finland and the Archipelago Sea have been defined. The Blue Economic sectors analysed were energy, the maritime cluster, maritime and coastal tourism, the blue bioeconomy and subsea resources. The drivers affecting the development of blue economy sectors by the year 2050 were identified by experts through Delphi-surveys and workshops. First, the drivers were explored using the PESTEL-classification: political, economic, social, technological, environmental and legal drivers. The main drivers were then analysed and presented in futures tables. The results of this analysis are discussed from the viewpoint of the maritime cluster and shipping. The most important shipping drivers identified are transnational in nature: global economic trends and environmental policies, which connect national and regional MSP with the global scale. Driver analysis supports the identification of the sector's needs in the context of MSP. Challenges encountered in the process are highlighted in this text.
\end{abstract}

\section{Introduction}

Marine Spatial Planning (MSP) processes inherently include the envisioning of future developments in marine and coastal areas [1]. Futures research methods facilitate regional knowledge creation and management; in particular, they fulfil the need to strengthen foresight activities and increase visionary capabilities at the regional level [2]. In futures studies, scenarios are widely used as a tool for collective learning, for reframing perceptions and to preserve uncertainty if it is pervasive. A central part of the scenario process is to understand and define the driving forces behind future changes [3].

\footnotetext{
* Corresponding author: riitta.pontynen@utu.fi
} 
In this study, the consideration of the driving forces, i.e. drivers, is a part of the examination of the alternative future scenarios concerning the regional blue economy in the Gulf of Finland and the Archipelago Sea in the Baltic Sea (Fig. 1). Here, the drivers are defined as external forces, which the individual actors cannot influence with their own means, but which affect the region's operational environment [4]. They are seen as contextual scenario elements that externally frame the conditions beyond the control of the relevant actors [5, cf. 2.].

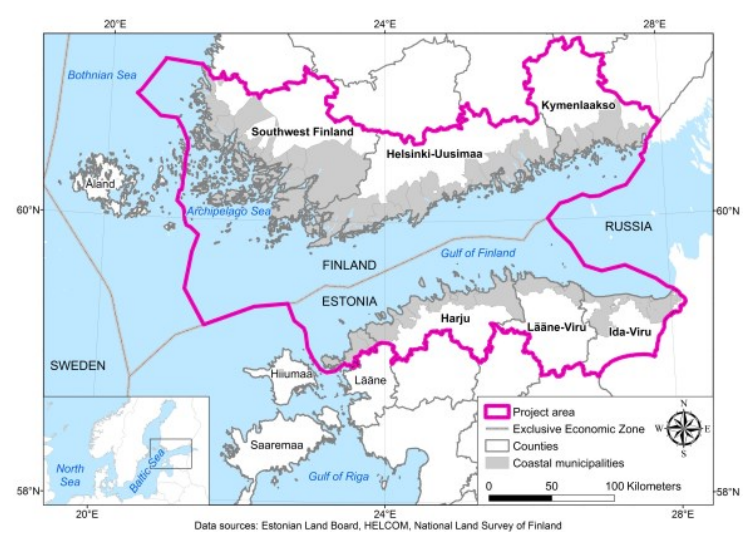

Fig. 1. Plan4Blue project area. [6]

This study explores drivers that may have major effects on the future development of the operational environment of regional blue economics and the use of coastal and sea space. Experts, as representatives of different MSP stakeholders, have extensive knowledge on the driving forces within their field of expertise. Thus, they play a crucial role in defining the drivers of regional change $[3,7]$. Their views are explored in this study.

The shallowness, narrow straits and numerous islands, along with the possibility of ice cover in winter, make the Baltic Sea one of the most challenging areas for navigation [8,9]. In addition, it is one of the most heavily trafficked sea areas in the world, and the Gulf of Finland is among the most congested sea areas of the Baltic Sea. It is anticipated that maritime transport in the Gulf of Finland will still increase, for example, due to the increases in Russian transport activity $[8,9,10]$. The area has large ports with lively passenger and cargo traffic, including increasing oil transport traffic. All this increases the risks associated with maritime transports in the Gulf of Finland and the Archipelago Sea [10]. The increases in maritime transport activities compete for space with the increasing leisure boating and other activities, making MSP processes highly important for the maritime transport and port businesses. Exploring drivers that influence the development of blue business sectors and their development prospects up to 2050 is crucial for scenario building. Understanding the drivers that affect the maritime cluster in the study area is crucial for the success of MSP processes.

The study is a part of the Plan4Blue project, which focuses on the building of cross-border MSP capacity [11]. Among other tasks, alternative future scenarios are produced based on the quantitative and qualitative data produced in the project. [12] 


\section{Methods}

\subsection{Defining Blue Economy Sectors}

In the first phase of the economic analysis and scenario process, the analysis included all existing blue economy sectors in the study area, to enable the selection of the most important ones. The sectors are based on EU definitions [e.g. 13, 14, 15], and the extent of the analysis was agreed upon with the project partners, considering, in particular, the views of MSP planners. The analysed blue economy sectors are: energy; the maritime cluster; tourism, culture, services for leisure activities; and the blue bioeconomy and subsea resources. These sectors were included in the quantitative economic analysis as well as the rounds of the Delphi-panel and the workshop in Helsinki, both of which took place in 2017.

This paper focuses on the drivers of the maritime cluster. The following subsectors of the maritime cluster were chosen for further investigation in the first phase of the economic analysis and scenario process:

- Fairways: Building, deepening and maintenance

- Ports: Building, expanding port and harbour areas, other water constructions

- Sea and coastal cargo transportation

- Sea and coastal passenger transportation

- Building of ships, clean tech and equipment for the vessels (manufacturing)

- Offshore construction (fixed or floating platforms)

- Warehousing and storage related to cargo transports

- Pilotage and towage of ships

- Demolition of ships

- Warehousing and storage of leisure boats

In the second phase, which took place in 2018, the analysis focused on the sub-sectors identified in the 2017 results.

\subsection{Delphi panel and workshops}

The Delphi method was selected because it is a structured communication technique based on the anonymity of the participants, allowing them to freely express and change their opinions during the process [e.g., 3]. On the other hand, the workshops offered direct communication and discussion between experts. The aim of the scenario workshops has been to complement and deepen the results of the Delphi questionnaires.

The Delphi studies in 2017 and 2018 were independent two-round questionnaires. The overall aim of both Delphi studies was to define the blue business sectors and drivers that are relevant to the future regional development of the Gulf of Finland and the Archipelago Sea. The 2017 Delphi and Helsinki workshop also explored, quite extensively, the perceptions of experts regarding the future locations and activities of the blue businesses. The drivers were assessed viewing the blue economy as a whole. Based on the Delphi and other economic surveys carried out in the Plan4Blue-project in 2017, the 2018 Delphi and Tallinn workshop focused more on the most important blue business sectors from the perspective of Maritime Spatial Planning, as well as on their sub-sectors.

With the help of an expertise matrix, a cross-boundary and multi-sectoral panel of experts was formed. It consisted of all the relevant blue economy business sectors, both from Finland and from Estonia. The business representatives were mainly from business support organizations and unions, as choosing individual companies might have emphasized their opinions excessively. In addition, there were only few academics in the panel, as the focus 
was on stakeholders that have concrete interests or activities in the coastal and sea areas, either in terms of business operations or sea-use planning.

In 2017, the panel consisted of 55 members that represented blue economy businesses, public authorities and NGOs from Finland and Estonia. For the Delphi rounds in 2018, the panel composition was checked. New members were recruited to balance the representation towards the business sectors that were the focus of the 2018 rounds. In this phase, the panel had 57 members.

The Delphi studies were performed through on-line questionnaires. In 2017 , the $1^{\text {st }}$ questionnaire was composed using the HARAVA tool [16] and sent on the $26^{\text {th }}$ of April. The second questionnaire was sent on the $14^{\text {th }}$ of June, just before the Helsinki workshop. The questionnaire included a mixture of Delphi-type and more traditional survey questions. The two rounds of Delphi in 2017 were answered by 43 panelists. In 2018, the first Delphi questionnaire was sent on February $16^{\text {th }}$ and the second on April $18^{\text {th }}$. Altogether, 16 replies were received. The questionnaire included statements on the development of the blue economy sectors that were related to the alternative scenarios. The 2017 questionnaires had identical Finnish, Estonian and English versions. The workshops and the 2018 Delphi were in English.

The first workshop was arranged in Helsinki on the $15^{\text {th }}$ and $16^{\text {th }}$ of June 2017, and the second one in Tallinn on the $23^{\text {rd }}$ and $24^{\text {th }}$ of January 2018 . The Helsinki workshop was attended by 40 participants, six of whom were Delphi panelists and 24 of whom were other invited experts. Of the experts, 9 participants were from Estonia and 21 from Finland. In the Tallinn workshop, there were altogether 41 participants. Of the experts, 17 were from Estonia and 6 from Finland. Four Delphi panelists attended the Tallinn workshop. In the Tallinn workshop, the working groups were designed to work from the point of view of the different blue economy sectors, whereas in Helsinki, the groups worked from the point of view of the blue economy as a whole.

\subsection{The classification and mapping of the drivers}

To extensively explore the external forces that may have impacted various blue economy sectors in the study area, the PESTEL approach was adopted. The concept was introduced by Aguilar [17] as the PEST analysis for the Business Environment Scanning Task. PESTEL is a tool to "help form the futures table" and it analyses the impacts of political, economic, social, technological, ecologic / environmental and legal changes. It is used in scenario processes to chart external factors and drivers, and it originates from economics. The timespan for a PESTEL analysis is usually considered to be 3-10 years, though when combined with a scenario process, it is possible to create structured descriptions of alternative futures, and those drivers that are central for an activity or a sector are explored in more detail [4].

One of the themes of the Delphi-questionnaire included the assessment of the drivers according to the PESTEL classification: an estimation of the major political, economic, social, technological, environmental and legal drivers affecting the development of the blue economy by the year 2050. Prior to the 2017 Delphi study, a set of general drivers that may have regional-level effects in the study area were selected based on the literature and the suggestions of project partners. According to Vuorinen [4], the strength and probability of the drivers, their positive or negative influence and the timespan of a change should be assessed. In the first questionnaire, the positive or negative influence were evaluated considering those drivers that are global megatrends already taking place, or based on political decision-making, thus already being intended to have a clear effect on the businesses in the study area. Regarding other drivers, the experts were asked to evaluate their 
significance on the human activities in the study area. In the questionnaire, respondents had the possibility to add or comment on the important PESTEL drivers in open questions.

In the Helsinki workshop, drivers were discussed as one of the three working group themes. The world café method [18] was used. Each of the three working groups contributed into three thematic working group sessions. Groups circulated the themes and complemented the previous discussions. The PESTEL drivers from the Delphi study, with some added drivers from the comments and literature, were presented to the drivers group. The participants selected the most important drivers and explained their reasons for choosing them. Based on the Delphi and workshop responses, key drivers for different blue economy sectors, e.g. for the maritime cluster, were identified by the research team. The importance of these drivers and their consequences was the focus of the Delphi-round of 2018 and the Tallinn workshop.

Participants of the Tallinn workshop and the Delphi panelists were asked to identify the three most important drivers for the specified blue economy sectors, e.g. the maritime sector. The Delphi panelists were asked to assess the possible effects of the drivers they selected. In the Tallinn workshop, the participants discussed the consequences and future developments of the most important drivers chosen in the working group.

\section{Results and discussion}

\subsection{Identification of drivers for the blue economy}

In the first Delphi study and the Helsinki workshop, environmental policies were viewed as the most important political driver, and their impact was assessed to be significantly positive. Other sectoral policies were considered important drivers as well, and the percentage of respondents was almost the same. Traffic policy was considered a positive factor by the respondents, as well as the industrial policies. The connection between increased political tensions in the Baltic Sea and strengthening EU integration was pointed out at the workshop. The issue of global security was also raised in the discussions, in particular related to tourism.

Both in the Delphi panel and in the workshop, global economy conditions and trends were considered to be the most important economic driver. In Delphi, it was closely followed by the regional economy conditions and trends. Globalization was considered to affect, in particular, the maritime industry, through the increasing demand for maritime transport. Global economy as a driver emphasizes the significance of ports and affects the volume of maritime transport, as well as the volume of shipbuilding orders. Maritime transport also affects the regional level in a positive way. In the case of the maritime cluster, the attitudes of customers and shippers influence the sustainable development of the sector. The aim of achieving a low carbon society was discussed from the perspectives of both economic and policy aspects.

Among the social drivers, ageing, urbanization and attitudes towards blue businesses were considered particularly important. These drivers are linked to trends and consumption habits, and thus to the future transport needs of the area. The selected technological drivers have many connections to the maritime cluster: clean tech innovations for blue businesses, increasing automatization and the overall development of ICT and digitalization. As one of the environmental drivers, the eutrophication of the sea was unanimously considered the most important driver in the Delphi-questionnaire in terms of its effect on the development of the region's blue economy by 2050. In the Helsinki workshop, climate change as a larger phenomenon was proposed to be included as a driver, thus combining many of the environmental drivers presented in the questionnaire. In Delphi, tight restrictions for environmental permits were considered the most important legal driver. In the workshop, 
environmental regulations and the permit process as a whole, including changes and restrictions, was mentioned the highest number of times.

While the causal relations were not discussed in depth, certain links between these drivers were identified. The level and extent of co-operation in the Baltic Sea Region was considered to be linked with the safety situation and stability of the Baltic Sea. For example, the relationship with Russia affects maritime transport via the ports of Finland and Estonia, and the future of transit cargo passing through Estonia and Finland. Environmental policies have an impact on the fuels used in shipping. Transport policy affects ship owners and ports.

\subsection{Drivers of the maritime cluster}

In the second phase, in 2018, the Delphi panelists believed there would be environmental benefits through economic development: strong economic growth would also bring economic benefits into that region. The regional economic situation would promote co-operation, and the better the situation, the more the amount of shipping would increase. It was noted that the trends of global economy always act as a foundation for the state of the maritime cluster. The economic situation controls supply and demand. The panelists assessed the environmental regulations and the chosen fuels, which affect the price levels of fuels and ports. The use of low-carbon fuels can support carbon neutrality. Energy efficiency and clean air were also considered important drivers.

The level of co-operation in the BSR - the safety situation and stability of the Baltic Sea area, combined with the regional economic situation as well as environmental regulations and legal practices, were considered extremely relevant to both the amount of cruise passengers in the BSR as well as cargo transport activities. Autonomous shipping was expected to revolutionize shipping altogether, even if the need for a crew would remain e.g. in the archipelago areas. Various climate conditions, for example ice cover and storms, were considered to affect what types of freight vessels can be operated, for example, in the BSR.

In the Tallinn working group, globalization, increasing economic growth and the growth of cargo volume were considered to have an influence on the land infrastructure of the maritime cluster. Larger port areas on land, better infrastructure and port-hinterland connections would be required. Increased ship size would require deeper fairways. It was also noted that global shipping means global solutions, as well. In terms of sustainable development, the profile of vessels may change. However, global economic growth was expected to have a larger effect in Asia and $3^{\text {rd }}$ world countries than in the BSR. Transit cargo would also provide an opportunity for the local operators and service providers. Possibilities for port expansion were discussed in relation to e.g. conservation areas near port areas. Offshore waiting areas would be needed to access the congested ports.

The attitudes of customers and shippers were expected to influence what types of cargo would be transported in the area, but also the ship owners' investments in clean tech and fuels. In the future, customers might be more willing to pay more for high-quality and clean tech solutions. Experts felt that attitudes could possibly be changed through information exchange and motivation building, and these actions should preferably be steered at the EUlevel. The results of the choices in the Delphi and the workshop in 2018 are presented in Błąd! Nie można odnaleźć źródła odwołania.Table 1 below.

Table 1. The most important drivers for the maritime sector in Delphi (2018/1) and the Tallinn working group (24 ${ }^{\text {th }}$ January, 2018) 


\begin{tabular}{|l|c|c|}
\hline Driver & $\begin{array}{l}\text { Mentions in Delphi n=14, } \\
\mathbf{4 1} \text { answers }\end{array}$ & $\begin{array}{l}\text { Mentions in the } \\
\text { Tallinn workshop n=4, } \\
\text { 10 answers }\end{array}$ \\
\hline Environmental regulations, legal practices & 8 & 4 \\
\hline $\begin{array}{l}\text { Conditions and trends of global economy, } \\
\text { globalization }\end{array}$ & 6 & \\
\hline $\begin{array}{l}\text { Clean tech / emissions from the maritime } \\
\text { cluster (energy efficiency) }\end{array}$ & 6 & \\
\hline $\begin{array}{l}\text { Fuels used in shipping (environmental } \\
\text { policy) }\end{array}$ & 5 & \\
\hline Regional economic situation & 4 & \\
\hline $\begin{array}{l}\text { Level of co-operation in the BSR - the } \\
\text { safety situation and stability of the Baltic } \\
\text { Sea area }\end{array}$ & 4 & \\
\hline ICT, digitalization & 3 & \\
\hline Attitudes of customers and shippers & 2 & \\
\hline Transport routes & 1 & \\
\hline Climate conditions & 1 & \\
\hline $\begin{array}{l}\text { Other: Development of autonomous ships } \\
\text { (without crew) }\end{array}$ & 1 & \\
\hline
\end{tabular}

In the context of globalisation and its consequences, some possible new roles and services for ports were envisioned that would have impact on port planning. For bigger ports, the multiuse of ports, mobility and new services were expected. These would include:

- Energy: serving offshore wind power plants (incl. maintenance)

- Tourism: more coastal cruises

- Cleantech would be situated in ports or in their vicinity

- Circular economy; for example, ports may produce energy from collected material and reuse waste in ports.

- Offshore platforms, also for multiuse by several blue economy sectors, as well as artificial islands, were considered future development options.

Potential synergies between cargo, passengers and energy were identified. New, future cargo types were discussed intensively. For example, in the future waste might become a new type of cargo. If the Arctic route through Finland was developed, there would be cargo through Finland from the north via railways or pipelines. Fossil fuels from the Arctic might be a new cargo type as well. This would create a new North-South transport corridor in the project area in addition to Russian and Eastern transit cargo.

Digitalisation and ICT were discussed as one of main drivers for the maritime sector. Automatization would impact vessels and ports, as well as their safety. Surveillance would be needed for the ports' offshore areas. Although most vessels would operate on automated fairways, there would be a risk for collisions between the autonomous and traditional uses of the fairways.

\subsection{Challenges of the process of identifying drivers}

In the first phase, the discussion of the long-term future developments at the regional level seemed to be challenging, even for experts. This was, to some extent, unexpected, because while the timeframe of 30-35 years is long in many societal and business issues, it is more familiar in land-use and regional planning, which is the sector that a majority of the experts represented. A longer timeframe is also preferable in MSP processes [e.g. 1].

While the idea of creating several alternative future scenarios and different opinions was emphasized, the Delphi responses and workshop discussions were about the current situation 
and issues or the familiar near-future changes that were already discussed, for instance, in the media, such as the development of autonomous shipping. Only a few truly visionary suggestions and ideas were presented, but the discussions around them did not expand. However, the discussions around the drivers deepened in Tallinn, which shows that the learning process for creating visions of the future developments takes time and iterations. The fact that the experts were more acquainted with certain issues on the table, each other and the moderators in the Tallinn workshop probably also affected the discussions in a positive way. This would be a similar result as in previous projects, where the transboundary planning is anticipated to benefit from informal situations, such as iterative face-to-face meetings that help create mutual trust and knowledge of the other parties [19, 20]. This is challenging, as the experts are busy people and the consideration of the planning issues requires time and familiarization, as well as the consideration of other stakeholders' views. In any case, stakeholder participation is necessary for the success of the MSP processes [e.g., 21].

It was beneficial to provide lists of the potential drivers in the workshops as a starting point for group discussions regarding their significance and effects on regional blue economics. The complex and multilevel chains of causal relationships formed by the drivers [cf. 17, 22. e.g. 23] were not discussed in depth. A few individual causal relationships were presented briefly in the Delphi studies and the workshops; and in the Tallinn workshop, the participants were encouraged to discuss the consequences of the drivers.

By definition, the contextual environment may only impact issues indirectly, but making the distinction between external factors and factors that, for instance, an individual organization can influence is often difficult [24]. These different levels of hierarchies were also noted by some of the experts in the workshops, but discussion on their connections and interrelations were not accomplished within the strict time-frames of the workshops.

\section{Main conclusions}

In the regional context, the international politics in the Baltic Sea region and the fluctuations of the global economy affect the general operational environment. In particular, the global economy and globalization directly affect maritime transport and the ports' business, probably even more than regional drivers in the study area. Additionally, environmental regulations for maritime transport are global, although in the Baltic Sea region the requirements are stricter. For the maritime cluster, this also offers possibilities for clean tech business.

The future changes of maritime transport are anticipated to have effects on sea use, and especially on the issues of safety and security in the study area, where other uses of the sea compete for space with maritime transport. Ports may acquire new roles and services if, for example, the study area develops more as a maritime transport corridor for international and Arctic trade. The positions of ports may also become increasingly important in serving different blue economy businesses, which may also have new spatial requirements. Planning decisions and politics will define whether the requirements of maritime transport and ports are favoured or ignored in the future.

The challenge for the experts working with questionnaires and in workshops is to vision the long-term future changes and thoroughly discuss complex and multilevel issues such as drivers. Our study gave hints that in MSP processes, the iterative rounds of discussions between experts are necessary in order to achieve successful long-term management decisions. The complex interrelations between the regional drivers should be studied more as the marine spatial planning processes are developed, as they have a central role in creating 
an understanding of the various possibilities of future development. The effects of the most important drivers for alternative future scenarios should be assessed through the examination of long-term development of trends and their interactions with maritime businesses. In addition, methods allowing experts from different stakeholder groups to participate in marine spatial planning as a part of the long-term planning, monitoring and management processes should be developed further.

The article is based to Delphi-panel and workshops realized as part of Plan4Blue project.

\section{References}

1. P. M. Gilliland and D. Laffoley. Key elements and steps in the process of developing ecosystem-based marine spatial planning. Mar. Policy 32, 787-796. (2008)

2. T. Uotila, H. Melkäs, V. Harmaakorpi. Incorporating futures research into regional knowledge creation and management. Futures 37, 849-866. (2005)

3. J. Maness. Techniques, Methods \& Applications in Futures Studies. EBSCO Publishing: eBook Collection (EBSCOhost). (2012)

4. T. Vuorinen. Strategiatyökirja. 20 työkalua. Talentum (2013).

5. R. Milestad, Å. Svenfelt. K.H Dreborg. Developing integrated explorative and normative scenarios: The case of future land use in a climate-neutral Sweden. Futures 60, 59-71. (2014)

6. T. Nylén. Basemap of Plan4Blue project area. (2017).

7. H. Ritchie, G. Ellis. 'A system that works for the sea'? Exploring Stakeholder Engagement in Marine Spatial Planning. J. Environ. Plann. Man 53:6, 701-723. (2010)

8. Baltic Lines. Baltic LINes: Shipping in the Baltic Sea - Past, present and future developments relevant for Maritime Spatial Planning. Project Report I. 35 p. (2016):

9. HELCOM BSEP 152. HELCOM Assessment on maritime activities in the Baltic Sea 2018. Baltic Sea Environment Proceedings No.152. Helsinki Commission, Helsinki. 253pp. (2018). Available at http://www.helcom.fi/Lists/Publications/BSEP152.pdf

10. WWF. Future Trends in the Baltic Sea. WWF Baltic Ecoregion Programme 2010). Available at

http://wwf.panda.org/what_we_do/where_we_work/baltic/publications/?194764/F uture-trends-in-the-Baltic-Sea

11. Plan4Blue project, available at http://www.syke.fi/projects/plan4blue

12. R.Pöntynen, A. Erkkilä-Välimäki, T. Nylén, R. Varjopuro, H. Nieminen, A. Lähteenmäki-Uutela, T. Pohjola, M. Roose, H. Uusitalo, J. Törrönen. Setting of Blue Growth Scenarios. Qualitative analysis based on expert opinions. (to be published).

13. European Commission / EUNETMAR. Study on Blue Growth, Maritime Policy and the EU Strategy for the Baltic Sea Region. Final report. (2013). Available at https://webgate.ec.europa.eu/maritimeforum/en/node/3550

14. Blue Growth. Opportunities for marine and maritime sustainable growth. COM (2012) 494 final.

15. Sustainable Blue Growth Agenda for the Baltic Sea Region (2014). Available at service.mvnet.de/php/download.php?datei_id $=132314$

16. HARAVA tool, available at https://dimenteq.fi/palvelut/harava/

17. F.J. Aquilar. Scanning the Business Environment. The Macmillan Company, New York. (1967) 
18. J. Brown. The World Café: Living Knowledge through Conversations that Matter. The Systems Thinker. 12:5. (2001).

19. Ruskule et al. Pan-Baltic stakeholders' dialogue on MSP: Synthesis report from PartiSEApate single-sector workshops held in 2013. (2014). Available at http://www.partiseapate.eu/wp-content/uploads/2014/08/Syntesis-report-from-panBaltic-Dialogues-2013.pdf

20. Baltic Scope 2017. Recommendations on maritime spatial planning across borders. Available at http://www.balticscope.eu/content/uploads/2015/07/BalticScope_OverallRecomen dations EN WWW.pdf

21. R.Pomeroy, F. Douvere. The engagement of stakeholders in the marine spatial planning process. Mar. Policy 32, 816-822. (2008)

22. G. Tovstiga, M. Aylward. Strategic Direction. Study Guide. Henley Business School. (2008).

23. R. J. A. Collins. Graphical Method for Exploring the Business Environment. Available at us-ers.ox.ac.uk/ kell0956/docs/PESTLEWeb.pdf (8.6.2017) (2010).

24. H.A. Wolters, J. Gille, J.M. de Vet, R.J. Molemaker. Scenarios for selected maritime economic functions. Futures 1:11. (2013) 